\title{
POMC overexpression in the ventral tegmental area ameliorates dietary obesity
}

\author{
Lourdes M Andino ${ }^{1}$, Daniel J Ryder ${ }^{1}$, Alexandra Shapiro ${ }^{1}$, Michael K Matheny ${ }^{1}$, Yi Zhang ${ }^{1,3}$, \\ Melanie K Judge ${ }^{1}$, K Y Cheng ${ }^{1}$, Nihal Tümer ${ }^{1,3}$ and Philip J Scarpace ${ }^{1,2}$ \\ Departments of ${ }^{1}$ Pharmacology and Therapeutics and ${ }^{2}$ Aging and Geriatrics, University of Florida College of Medicine, PO Box 100267, Gainesville, \\ Florida 32610, USA \\ ${ }^{3}$ Department of Veterans Affairs Medical Center, Gainesville, Florida 32608, USA \\ (Correspondence should be addressed to P J Scarpace at Department of Pharmacology and Therapeutics, University of Florida College of Medicine; \\ Email: scarpace@ufl.edu)
}

\begin{abstract}
The activation of proopiomelanocortin (POMC) neurons in different regions of the brain, including the arcuate nucleus of the hypothalamus (ARC) and the nucleus of the solitary tract curtails feeding and attenuates body weight. In this study, we compared the effects of delivery of a recombinant adeno-associated viral (rAAV) construct encoding POMC to the ARC with delivery to the ventral tegmental area (VTA). F344 $\times$ Brown Norway rats were high-fat $(H F)$ fed for 14 days after which self-complementary rAAV constructs expressing either green fluorescent protein or the POMC gene were injected using coordinates targeting either the VTA or the ARC. Corresponding increased POMC levels were found at the predicted injection sites and subsequent $\alpha$-melanocyte-stimulating hormone levels were observed.
\end{abstract}

Food intake and body weight were measured for 4 months. Although caloric intake was unaltered by POMC overexpression, weight gain was tempered with POMC overexpression in either the VTA or the ARC compared with controls. There were parallel decreases in adipose tissue reserves. In addition, levels of oxygen consumption and brown adipose tissue uncoupling protein 1 were significantly elevated with POMC treatment in the VTA. Interestingly, tyrosine hydroxylase levels were increased in both the ARC and VTA with POMC overexpression in either the ARC or the VTA. In conclusion, these data indicate a role for POMC overexpression within the VTA reward center to combat HF-induced obesity.

Journal of Endocrinology (2011) 210, 199-207

\section{Introduction}

Melanocortins are a group of peptide hormones that are the resulting cleavage products of a common precursor peptide known as proopiomelanocortin (POMC). In the brain, POMC is found in regions of the pituitary gland, certain areas of the hypothalamus, particularly the arcuate nucleus (ARC) and the nucleus of the solitary track (NTS) in the brainstem (DeBold et al. 1988). The cleaved peptides are released after the action of two proprotein convertases known as protein convertase subtilisin/kexin type 1 and 2 (PC1 and PC2 respectively; Benjannet et al. 1991). Upon activation, one of the peptide hormones believed to be in part responsible for the decreases in food intake and increases in energy expenditure is $\boldsymbol{\alpha}$-melanocyte-stimulating hormone $(\alpha-\mathrm{MSH}$; Cone 2005). This peptide exerts its effects by binding to the melanocortin 3 and 4 receptors (MC3R and MC4R respectively). In the ARC, the melanocortin system is downstream of the leptin signaling pathway and is a key leptin target. Leptin activates POMC neurons in the ARC and causes increases in POMC expression as well as decreases in agouti-related protein $(\mathrm{AgRP})$, an inverse agonist of the MC3R and MC4R (Gropp et al. 2005, Luquet et al. 2007). The melanocortins are potent anorexic and weight reducing agents (Garfield et al. 2009), and transgenic male mice overexpressing $\alpha$-MSH are leaner than control counterparts (Savontaus et al. 2004). Melanocortins are particularly effective in preventing high-fat (HF)-induced weight gain (Li et al. 2004) and $\alpha$-MSH overexpression attenuates the metabolic effects of a HF diet (Lee et al. 2007).

The melanocortin receptors, specifically MC4R have been found in brain regions both within and outside of the hypothalamus, implicating areas other than the ARC as potential targets for energy homeostatic regulation by melanocortins (Lasaga et al. 2008). Although MC4R mRNA localization to the reward center in the ventral tegmental area (VTA) has been identified in some studies (Alvaro et al. 1996, Leriche et al. 2007), this has not been confirmed in another study (Kishi et al. 2003). In addition, no POMC-producing neurons have been identified in the VTA. However, POMC neurons in the ARC project widely in the CNS (Cone 2005, Balthasar 2006). It is possible that POMC product(s) such as 
$\alpha-\mathrm{MSH}$ may act directly upon MC4R in the VTA to modulate energy ingestion and balance. The circuitry of the VTA has a role in reward and motivation as related to decisions of food ingestion. The VTA, in particular, is a region of the brain that has been found to be responsive to leptin administration by reducing HF food consumption (Hommel et al. 2006, Morton et al. 2009). The studies herein were then undertaken to determine whether chronic overexpression of POMC in the VTA would have a long-term effect on HF feeding behaviors, energy expenditure and ultimately, weight loss.

To facilitate the expression of POMC in the VTA, we enlisted the use of recombinant adeno-associated viral vectors (rAAV). Specifically, we engineered self-complementary forms that are double-stranded upon delivery and therefore eliminate the rate-limiting step of second-strand synthesis needed for viral load expression (McCarty et al. 2001). For a long time, rAAV vectors have been the preferred vectors of choice because of their ability to transduce dividing and nondividing cells (Lu et al. 2009), their lack of pathogenicity (Muzyczka 1992, Berns \& Giraud 1996), and their ability to express for long periods of time (Lu et al. 2009).

Previous studies by our laboratory have been able to harness the particulars of this gene delivery system and demonstrate the efficacy of rAAV-mediated delivery of POMC into the ARC of the hypothalamus and the NTS of the brainstem (Li et al. 2005, 2007). Sustained POMC expression was demonstrated in these two sets of sentinel studies. Overexpression in the ARC was efficacious in aged obese F344 $\times$ BN rats compared with young lean rats. However, the reductions in food consumption and body weight attenuated within weeks, likely due to downregulation of melanocortin receptors and/or increased AgRP. On the contrary, overexpression in the NTS, a brain region in which AgRP is not expressed, resulted in prolonged hypophagia and sustained abatement of body weight gain (Li et al. 2005, 2007).

Collectively, these gene delivery interventions and other studies involving pharmacological administration of melanocortins suggest that the activation of the melanocortin pathway is particularly effective in the obese state. Considering the importance of the VTA in the rewarding and reinforcing aspects of palatable food consumption, we reasoned that melanocortin activation of the VTA could be as or more efficacious than activation of the ARC in tempering $\mathrm{HF}$ food consumption and body weight gain. To these ends, we overexpressed POMC in the VTA or in the medial basal hypothalamus targeting the ARC and examined resultant $\mathrm{HF}$ food intake, energy expenditure and body weight gain.

\section{Materials and Methods}

\section{$r A A V$ constructs}

The scPOMC rAAV construct was created by cloning the full-length POMC insert into a self-complementary rAAV backbone containing a mutated terminal repeat. This feature is capable of allowing the DNA to fold into a double-stranded configuration. This construct contained the rAAV2 terminal repeats and POMC expression was under the control of the chicken $\beta$-actin promoter. Constructs were subsequently pseudopackaged into rAAV1 capsids following previously described methods (Andino et al. 2008).

\section{Experimental animals and diet}

All animals were cared for according to the principles of the Guide to the Care and Use of Experimental Animals and protocols were approved by the University of Florida IACUC committee. Initially, 3-month-old F344 X Brown Norway rats (National Institute on Aging) were allowed to acclimate for 7 days to the animal facility upon arrival, feeding on standard rodent chow $(17 \% \mathrm{kcal}$ from fat, $3 \cdot 41 \mathrm{kcal} / \mathrm{g}$, diet 7012 , Harlan Teklad, Madison, WI, USA). HF feeding began the subsequent week using a HF diet containing $(60 \% \mathrm{kcal}$ from fat, $5 \cdot 24 \mathrm{kcal} / \mathrm{g}$, Research Diets D-12492, New Brunswick, NJ, USA). Animals were HF fed for 2 weeks until caloric intake had normalized. At this time, rAAV was administered, and animals were kept on the HF diet for the duration of experimentation. Animals were individually housed under standard $12 \mathrm{~h}$ light:12 h darkness cycle. Body weight and food intake were assessed daily to three times a week.

\section{Stereotaxic injections}

A single dose of pTR-scPOMC containing $4 \cdot 17 \times 10^{13}$ particles $/ \mathrm{ml}$ was administered unilaterally to the experimental groups into either the VTA $(N=7)$ or the ARC $(N=7)$. For the control group, animals received a single unilateral injection into either the VTA $(N=4)$ or the ARC $(N=3)$ of a similar construct containing green fluorescent protein (GFP) at a titer of $4 \cdot 26 \times 10^{12}$ particles $/ \mathrm{ml}$. Using the brain atlas by Paxinos and Watson, the coordinates for injection into the VTA were $5.3 \mathrm{~mm}$ posterior to Bregma, $8.5 \mathrm{~mm}$ ventral from the skull surface, and $-0.6 \mathrm{~mm}$ lateral from the midsagittal suture. Also using the brain atlas, ARC injection coordinates used were $3.2 \mathrm{~mm}$ posterior to Bregma, $9 \cdot 0 \mathrm{~mm}$ ventral from the dura, and $-0.3 \mathrm{~mm}$ lateral from the midsagittal suture. Note that the ARC injection coordinates places the needle tip directly above the ARC. This was done to reduce destruction to the ARC tissue. Also, using a dye, we empirically determined that these injection coordinates successfully delivered virus to the ARC or VTA. For all animals, $0.75 \mu \mathrm{l}$ of the respective virus was injected and the needles remained in place for $5 \mathrm{~min}$ before retracting. At the time of surgery, rats received an injection of the analgesic Buprenex at a concentration of $0.05 \mathrm{mg} / \mathrm{kg}$ (Reckitt and Colman, Richmond, VA, USA).

\section{Oxygen consumption}

Oxygen consumption was measured 48 days post gene delivery using an Oxygen Analyzer model S-3A 
(AEI Technologies, Naperville, IL, USA). Animals were placed into individual chambers without food or water and allowed to acclimate for $30 \mathrm{~min}$ with a flow rate of $11 / \mathrm{min}$. Ten measurements were recorded per minute and each animal was recorded every $7 \mathrm{~min}$. The total amount of time recorded was $96 \mathrm{~min}$. Values were adjusted for the differences in surface to mass ratio, thus expressed as $\mathrm{ml} / \mathrm{min}$ per $\mathrm{kg}^{0 \cdot 67}$.

\section{Time-domain nuclear magnetic resonance}

Body adiposity was assessed using time-domain nuclear magnetic resonance (TD-NMR) with a Minispec lean fat analyzer (Bruker Optics, Inc., The Woodlands, TX, USA) on day 84 post gene delivery, following previously described methods (Tinsley et al. 2004).

\section{Tissue harvesting}

Rats were killed by thoracotomy under $150 \mathrm{mg} / \mathrm{kg}$ pentobarbital anesthetic 100 days after gene delivery. Subsequently, $40 \mathrm{ml}$ of cold saline were perfused through the circulatory system. The brown adipose tissue (BAT), epididimal, perirenal, and retroperitoneal white adipose tissues (EWAT, PWAT, and RTWAT respectively) were each excised and their individual weights recorded. In addition, $2 \mathrm{~mm}$ coronal sections containing the regions of the VTA and ARC were sliced and a punch of the respective regions were taken as subsequently described. Aligning a straight edge razor blade with the optic tract $(-1.5 \mathrm{~mm}$ posterior to Bregma), a $2 \mathrm{~mm}$ caudal coronal section was cut. Thereafter, a $1 \mathrm{~mm}$ circumference brain punch (Stoelting, Wood Dale, IL, USA) was used to excise regions centered around the ARC, the ventromedial hypothalamic nucleus, the dorsomedial hypothalamic nucleus, the lateral hypothalamic region and as a negative control, a region outside of the hypothalamus, denoted as 'Outer'. Similarly, aligning a straight edge razor blade with the caudal end of the hypothalamus $(-5 \mathrm{~mm}$ posterior to Bregma) a coronal section was cut $2 \mathrm{~mm}$ posterior. Thereafter, a $1 \mathrm{~mm}$ brain punch was used to biopsy regions of the VTA, a region slightly dorsal to the VTA defined as 'VTA adjacent' and a region centered around the substantia nigra. All punches were taken bilaterally.

\section{Preparation of $R N A$ lysates}

The bilateral brain biopsies from three animals were pooled together for each region of the brain that was punched out for each treatment group. The remaining animals in each group were used for protein lysates. These pooled tissue samples were then processed for RNA isolation using RNAqueous-Micro kit (Ambion/Applied Biosystems, Foster City, CA, USA). RNA was then quantified using a Nanodrop ND-1000 spectrophotometer (Thermo Scientific, Wilmington, DE, USA).

\section{Real-time PCR}

Total RNA (100 ng) was reverse transcribed using the highcapacity cDNA Reverse Transcription Kit (Applied Biosystems) containing random primers. Real-time PCR primers were custom designed using the software available on the Applied Biosystems website. The primers were engineered to exclusively detect and amplify the AAV delivered POMC DNA (sense 5'-CGCCCCGGCTCTGA and antisense 5'-GCGGAAAGGCAGCTCTCT). Quantitative real-time PCR was performed in an Applied Biosystems StepOne Real-Time PCR machine. These primer sets were simultaneously used in combination with predesigned Taqman gene-specific primers for the 18S RNA (Applied Biosystems) in conjunction with Taqman Fast Universal PCR Master Mix (Applied Biosystems) according to the manufacturer's instructions. POMC values were normalized to the $18 \mathrm{~S}$ RNA and then expressed as fold increase over the 'Outer' area to normalize amongst groups.

\section{Preparation of protein lysates}

Bilateral punches from each animal were individually processed for protein extraction with 3-4 animals per group. The remaining animals in each group were processed for RNA lysates. Briefly, tissue biopsies were homogenized in homogenization buffer (10 mM Tris, $\mathrm{pH} 6 \cdot 8,2 \%$ SDS) containing Halt Protease Inhibitor Cocktail (Pierce, Rockford, IL, USA). Quantification of lysates was carried out using the DC Protein Microassay procedure (Bio-Rad) following the manufacturer's protocol.

\section{$R I A$}

A RIA for $\alpha-\mathrm{MSH}$ was performed by $5 \mu \mathrm{g}$ of total protein lysate according to the manufacturer's protocol (Phoenix Pharmaceuticals, Burlingame, CA, USA).

\section{Western blotting}

Protein lysates (ARC and BAT, 2.5 $\mu \mathrm{g}$; VTA, $0.5 \mu \mathrm{g}$ ) were separated using SDS-PAGE and electrotransferred onto nitrocellulose membranes (Bio-Rad). Antibodies specific to uncoupling protein 1 (UCP1; Millipore, Billerica, MA, USA) diluted 1:400, TH (Pel-freez, Rogers, AK, USA) diluted 1:8000, or MC4R (Cayman Chemical, Ann Arbor, MI, USA) diluted 1:3000 were used. Immunoreactivity was measured on a Storm860 Phosphorimager (GE Healthcare Life Sciences, Piscataway, NJ, USA) after revealing blots with ECL Plus (GE Life Sciences).

\section{Statistical analysis}

Results are expressed as means \pm s.E.M. One-way ANOVA was used for analysis of caloric intake, oxygen consumption, UCP1 levels, adipose tissue deposits and RIAs. When the 
main event was significant, a post hoc test (Tukey method) was applied to determine individual differences between means. Two-tailed Student's $t$-test was used for analysis of body weight measurements.

\section{Results}

\section{Food consumption and body weight}

At the onset of gene delivery (day 0), the body weights of all three groups maintained on high fat were comparable $365 \pm 10,363 \pm 12$, and $358 \pm 13 \mathrm{~g}$ for the VTA, ARC, and GFP treated groups respectively. Because the physiology of the GFP groups injected into either the ARC $(N=3)$ or the VTA $(N=4)$ were similar, we grouped these animals into one GFP control group. Upon delivery of the AAV vectors, the animals lost a maximum of $10 \mathrm{~g}$ by day 4 due to the surgical intervention. This effect quickly dissipated and by day 5 , all of the animals were properly recovering and gaining weight.

rAAV administration of POMC into the ARC and VTA resulted in an attenuation in $\mathrm{HF}$-induced body weight gain beginning on day 26 post injection (Fig. 1A) with VTAinjected animals reaching significant levels of weight attenuation beginning at this point $(P<0 \cdot 01)$. From this day onward, the body weight curves of the control and POMC-treated animals continued to diverge all throughout the 100 days of experimentation. Animals that were overexpressing POMC in the ARC began to have a significant divergence in body weight beginning on day $30(P<0 \cdot 05)$ and continuing throughout the experiment. At termination, GFP animals had gained $107 \mathrm{~g}$ whereas the ARC and VTA treated groups had gained significantly less (85 and $66 \mathrm{~g}$ respectively). Interestingly, throughout the course of the experiment the intake in HF food did not differ amongst the three groups with an average caloric intake of $69 \mathrm{kcal} /$ day (Fig. 1B).

\section{Oxygen consumption}

The substantial abatement of dietary weight gain in the absence of diminished food consumption suggests increased energy expenditure. Resting oxygen consumption was assessed as a measure of energy expenditure and recorded 48 days following rAAV-POMC gene delivery. The results are expressed as whole-body oxygen consumption normalized to body weight. Values were found to be elevated when either the ARC or the VTA rAAV-POMC treated groups were compared with controls. Values for GFP-treated animals were $13.8 \mathrm{ml} / \mathrm{min}$ per $\mathrm{kg}^{0.67}$ and found to increase to $15.4 \mathrm{ml} / \mathrm{min}$ per $\mathrm{kg}^{0.67}$ for ARC-treated animals and significantly increased to $17 \cdot 7 \mathrm{ml} / \mathrm{min}$ per $\mathrm{kg}^{0 \cdot 67}(P<0 \cdot 001)$ in animals treated in the VTA. In addition, values were significantly elevated in the VTA group compared with the ARC treated group $(P<0 \cdot 05$; Fig. 2A).
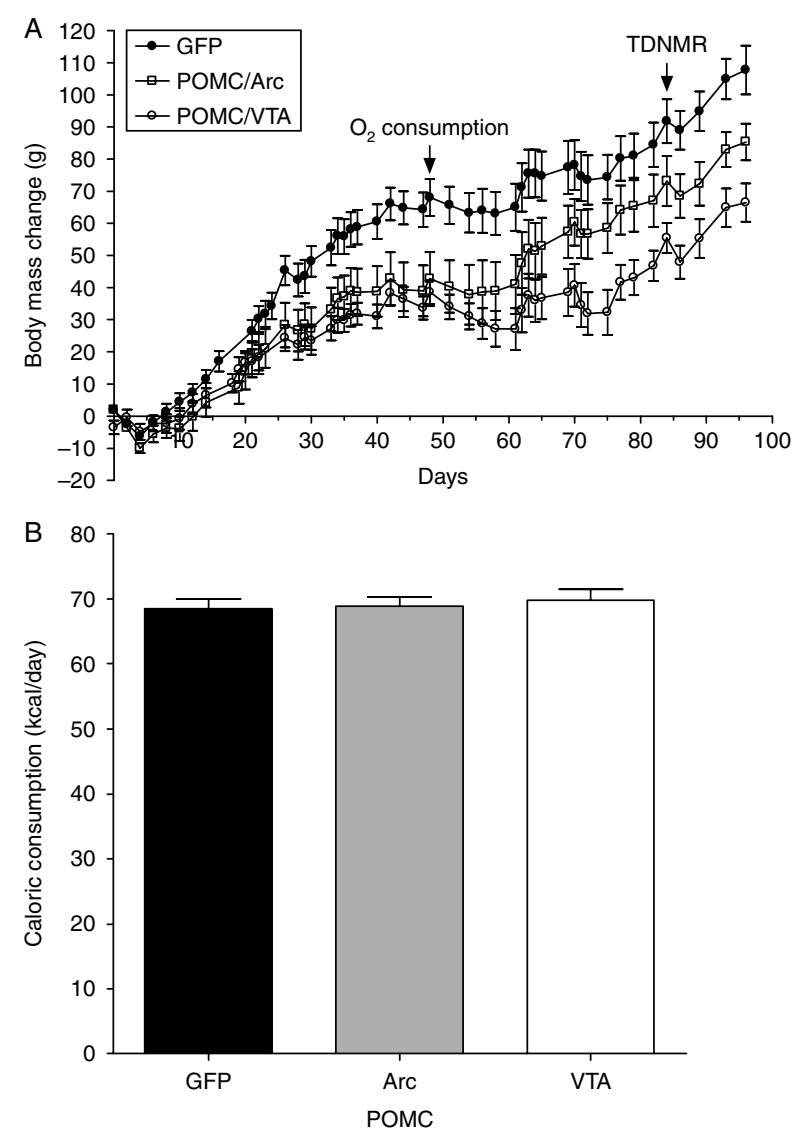

Figure 1 Body weight and caloric intake. Body weight change (A) in 4-month-old $344 \times B N$ rats that were injected into either the VTA (open circles) or the ARC (squares) with rAAV-POMC or rAAV-GFP (closed circles), the control group. Beginning on day 26 post gene delivery, significantly smaller increases in body weight gain were observed in VTA-treated animals compared with controls $(P<0 \cdot 01)$. As compared with controls, significantly smaller increases in body weight gain were observed in ARC-treated animals beginning on day $30(P<0 \cdot 05)$. The differences in weight gain amongst the ARC and VTA treated groups began to significantly diverge $(P<0 \cdot 05)$ on day 86 throughout the duration of the experiment. Assessments including oxygen consumption and TD-NMR were measured on days 48 and 85 respectively. Average caloric intake (B) did not differ amongst any of the three groups. Values represent the mean \pm s.E.M. of seven rats per group.

\section{BAT UCP1 levels}

Because melanocortins have been shown to stimulate brown fat (BAT) thermogenesis, we thus assessed the protein levels of UCP1 in the harvested BAT of the treated animals, a known marker for enhanced thermogenesis (Cannon \& Nedergaard 2004). Animals treated in the ARC had a greater than twofold increase in UCP1 levels and VTA-treated animals had a significant $2 \cdot 4$-fold increase $(P<0 \cdot 01)$ in BAT UCP1 protein levels (Fig. 2B). Upon performing correlation analysis amongst the oxygen consumption levels and the UCP1 levels, 

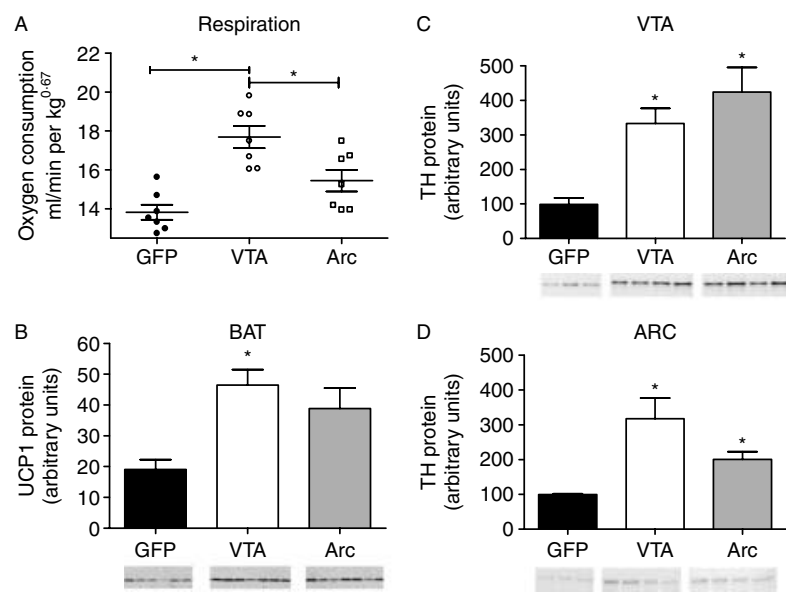

Figure 2 Physiological assessments. (A) Oxygen consumption measured 48 days post gene delivery. Values represent the mean \pm s.E.M. of seven rats per group. $P<0 \cdot 001$ by one-way ANOVA with post hoc Tukey test. (B) Uncoupling protein 1 (UCP1) levels in brown adipose tissue (BAT). Values represent the mean \pm S.E.M. of six to seven rats per group. (C) TH protein levels in VTA or (D) ARC following POMC overexpression in VTA or ARC. Values represent the mean \pm S.E.M. of three to four rats per group. ${ }^{*} P<0 \cdot 01$ by one-way ANOVA with post hoc Tukey test.

we found a strong correlation $\left(P<0 \cdot 01, r^{2}=0 \cdot 31\right)$, suggesting that increases in oxygen consumption were due to BAT thermogenesis.

\section{Tyrosine hydroxylase protein levels}

Tyrosine hydroxylase $(\mathrm{TH})$ protein levels were examined in the ARC and VTA following POMC gene delivery. With POMC targeted to the VTA, there was a three- to fourfold increase in TH protein in the VTA and ARC (Fig. 2C and D). Similarly, following POMC treatment in the ARC, TH protein levels were elevated twofold in the ARC (Fig. 2D) and fourfold in the VTA (Fig. 2C).

\section{Body composition assessment}

Levels of adiposity, lean and fluid mass in each of the treated groups were assessed by TD-NMR on day 85 post gene delivery. Because there was an overall attenuation in body weight gain in the ARC and VTA treated groups, we chose to express the TD-NMR values in total grams observed for each component as well as percent body fat. The amounts of lean mass and fluid levels were similar in both the ARC and VTA and across treatment compared with controls (Table 1). Conversely, the levels of fat observed in the VTA treated group were significantly less $(P<0 \cdot 05)$ than their control-treated counterparts, whereas percent body fat was significantly reduced in both ARC $(P<0 \cdot 05)$ and VTA $(P<0 \cdot 001)$ treated rats compared with control (Table 1).
At death, select adipose tissues were dissected and weighed. By weight, all adipose tissues significantly decreased in the VTA-treated animals compared with controls. Decreases in percentages of BAT $(29 \%, P<0 \cdot 05)$, peritoneal adipose tissue (PWAT, 51\%, $P<0.001$ ), epididymal adipose tissue (EWAT, $42 \%, P<0 \cdot 01$ ), and retroperitoneal adipose tissue (RTWAT, 54\%, $P<0 \cdot 01$ ) were observed (Fig. 3). Although levels did not reach significance in the ARC-treated animals compared with controls, there was a trend toward decreased fat mass in this group.

\section{Expression levels of $A A V$-mediated POMC $m R N A$}

Tissue levels of rAAV-derived POMC mRNA were quantified using real-time PCR in each treatment group in each of the brain regions biopsied. Primers were designed to distinguish between endogenous plus viral (POMC total) and exclusively viral-derived POMC mRNA, and the localization of viral-derived POMC mRNA was used as an indicator of viral spread. The values were normalized to an arbitrary outer region punch that was found to have negligible amounts of viral POMC (Outer) and values were expressed as fold increase over this outer area. In the animals that were injected in the VTA (Fig. 4A), the overwhelming majority of the virus (over 2400-fold increase) was detected at the site of injection with small amounts found in the area immediately adjacent to the VTA (VTA-A, 150-fold) and even smaller amounts found (56-fold) in the substantia nigra (SN). Similarly, ARC-treated animals (Fig. 4B) had most of the POMC expression within the ARC (over 360-fold increase) although the neighboring regions of the dorsomedial and ventromedial hypothalamus (DMH and $\mathrm{VMH}$ ) did have detectable increases in viral genomes (130- and 70-fold increases respectively).

Interestingly, using the POMC primers that were capable of detecting total POMC (viral-derived plus endogenous), very similar ubiquitous levels of POMC were detected in the GFP-treated animals in the various brain punch regions (data not shown). In addition, in all of the different punches assayed, our real-time PCR results for protein convertase subtilisin/kexin type 2 demonstrated the ubiquitous presence of this enzyme throughout the hypothalamus, VTA and even the outer uninjected region (data not shown).

Table 1 Time-domain nuclear magnetic resonance body assessment. Values are mean \pm s.E.M. of six to seven rats per group

\begin{tabular}{|c|c|c|c|}
\hline & GFP & ARC & VTA \\
\hline Fat (g) & $125 \cdot 54 \pm 5 \cdot 47$ & $115 \cdot 20 \pm 5 \cdot 64$ & $105 \cdot 51 \pm 3 \cdot 39 *$ \\
\hline Fat $(\%)$ & $27 \cdot 86 \pm 0 \cdot 25$ & $26 \cdot 34 \pm 0.43^{*}$ & $25 \cdot 09 \pm 0 \cdot 37^{* *}$ \\
\hline Lean $(g)$ & $367 \cdot 01 \pm 8 \cdot 22$ & $262 \cdot 51 \pm 9 \cdot 74$ & $258 \cdot 51 \pm 4 \cdot 10$ \\
\hline Fluid (g) & $38 \cdot 98 \pm 1 \cdot 28$ & $37 \cdot 43 \pm 1 \cdot 45$ & $36 \cdot 13 \pm 0 \cdot 72$ \\
\hline
\end{tabular}

${ }^{*} P<0 \cdot 05,{ }^{* *} P<0 \cdot 001$ by one-way ANOVA with post hoc Tukey's test. 

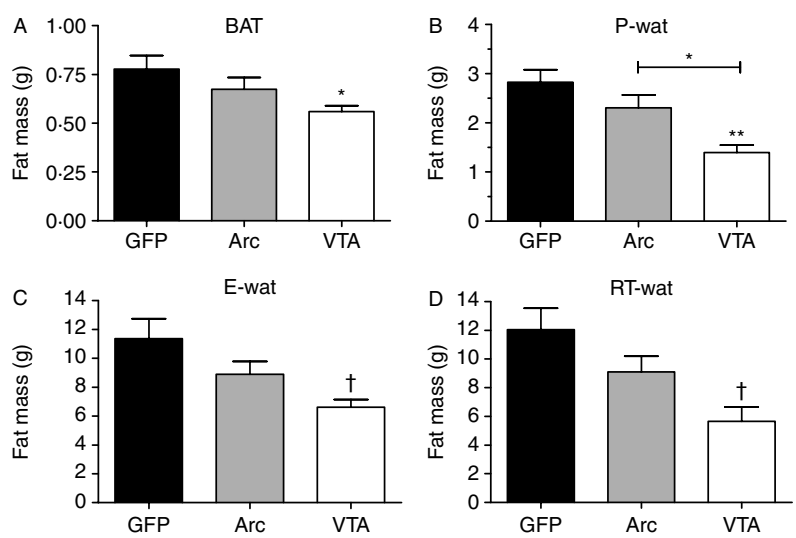

Figure 3 Weights of diverse adipose tissue reserves. Upon killing adipose tissues were excised and gross weights were assessed. (A) Brown adipose tissue (BAT), ${ }^{*} P<0 \cdot 05$ in VTA versus GFP; (B) perirenal white adipose tissue (PWAT), ${ }^{* *} P<0.001$ in VTA versus GFP, $* P<0 \cdot 05$ in VTA versus ARC; (C) epididymal white adipose tissue (EWAT), ${ }^{+} P<0 \cdot 01$ in VTA versus GFP; and (D) retroperitoneal white adipose tissue (RTWAT), ${ }^{\dagger} P<0.01$ in VTA versus GFP. Values represent the mean \pm s.E.M. of six to seven rats per group with analysis by one-way ANOVA with post hoc Tukey test.

\section{Levels of $\alpha-M S H$}

To determine whether POMC overexpression resulted in elevated $\alpha-\mathrm{MSH}$, the levels of this peptide were assessed in protein lysates from micropunches centered around the targeted brain regions. Specifically, in the VTA and ARC, $\alpha$-MSH levels were greater when the overexpression was directed to each individual region than when directed to the other, i.e. when overexpressed in ARC, $\boldsymbol{\alpha}$-MSH levels in ARC were greater than in VTA and vice versa (Fig. 5). Expression in the ARC (Fig. 5A) resulted in significant $\alpha$-MSH levels in the ARC $(P<0 \cdot 05)$ as well as elevated $\alpha-\mathrm{MSH}$ levels in regions near the ARC as evidenced in the DMH $(P<0 \cdot 01$, Fig. 5B), VMH $(P<0 \cdot 05$, Fig. 5 C), lateral hypothalamus (LH, $P<0 \cdot 05$, Fig. $5 \mathrm{D}$ ) but not $\mathrm{SN}$ (Fig. $5 \mathrm{E}$ ), or VTA (Fig. 5F). Because the VTA and hypothalamus have reciprocal neural projections, it was not a surprise that POMC overexpression in the VTA resulted in increases in $\alpha-\mathrm{MSH}$ levels in the VTA $(P<0 \cdot 01$, Fig. $5 \mathrm{~F})$ as well as in two regions in the hypothalamus, the DMH $(P<0 \cdot 01)$ and LH $(P<0 \cdot 05$; Fig. $5 \mathrm{~B}$ and $\mathrm{D})$, as well as in a region near the VTA, the $\mathrm{SN}$ $(P<0 \cdot 05$, Fig. 5E).

\section{MC4R levels}

We probed specifically for MC4R protein level in the VTA of F344 $\times$ BN rats, but were unable to confirm immunoreactivity for MC4R protein in the VTA. Although a commercial antibody for the MC4R identified a protein corresponding to the correct molecular weight of the glycosylated MC4R in the VTA $(55 \mathrm{kDa})$, this same protein was unexpectantly identified in brain tissue from $M C 4 R$ knockout mice (data not shown).

\section{Discussion}

This study identifies a role for POMC overexpression specifically in the VTA in combating diet-induced obesity. We employed a double-stranded (self-complementary) AAV vector encoding POMC to overexpress POMC in two regions of the brain - the ARC, a region recognized for its importance in energy homeostasis, and the VTA, a region of the brain involved in reward and motivation. Whereas the efficacy of POMC or more specifically, one of its peptide products, $\boldsymbol{\alpha}$-MSH and its analogs, is well described when applied to hypothalamus or NTS, the role of melanocortins in the VTA has not been previously characterized. Although POMC-producing neurons have not been found in the VTA, it is possible that neuronal projections from the ARC or NTS to the VTA could provide source(s) for native $\alpha$-MSH levels. However, it is controversial whether there are MC4Rs in the VTA. There have been reports of POMC (Leriche et al. 2007) and MC3R and MC4R mRNA in the VTA (Alvaro et al. 1996), but another report (Kishi et al. 2003) and our current study were unable to confirm the existence of MC4R protein in the VTA. Despite the uncertainty of the presence of MC4Rs, overexpression of POMC in the VTA tempers longterm body weight gain in HF-fed animals, and surprisingly, does so as effectively as overexpression of POMC in the ARC, suggestive of MC4R function in the VTA.

Interestingly, in our study, neither the VTA-injected animals nor the ARC-injected group had any significant change in their daily caloric consumption of the HF diet. This is similar to our previous study with delivery of rAAV-POMC into the ARC of lean, F344 $\times$ Brown Norway rats, where caloric consumption was unchanged in animals maintained on chow (Li et al. 2007). Similar findings were also found in a study by Lee et al. (2007) using a transgenic mouse overexpressing $\alpha-\mathrm{MSH}$ in the hypothalamus demonstrating weight gain abatement but little difference in caloric intake. The mechanism behind this uncoupling of food intake
A

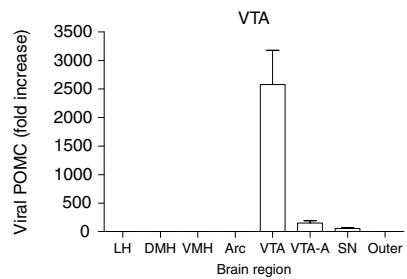

B

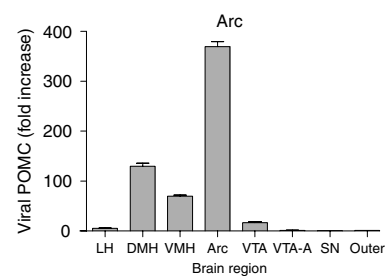

Figure 4 Real-time PCR assessments. Viral POMC mRNA levels were measured in either the VTA (A) or the ARC (B) regions to assess AAV distribution. Three punches for each region were pooled together to extract RNA. PCRs were run in duplicate and regions assessed included arcuate nucleus (ARC), dorsomedial hypothalamus $(\mathrm{DMH})$, ventromedial hypothalamus $(\mathrm{VMH})$, lateral hypothalamus (LH), ventral tegmental area (VTA), an area immediately adjacent to the VTA (VTA-A), substantia nigra (SN), and an outer uninjected region (Outer). Values were normalized to $18 \mathrm{~S}$ RNA and expressed as fold increase over Outer \pm s.E.M. 

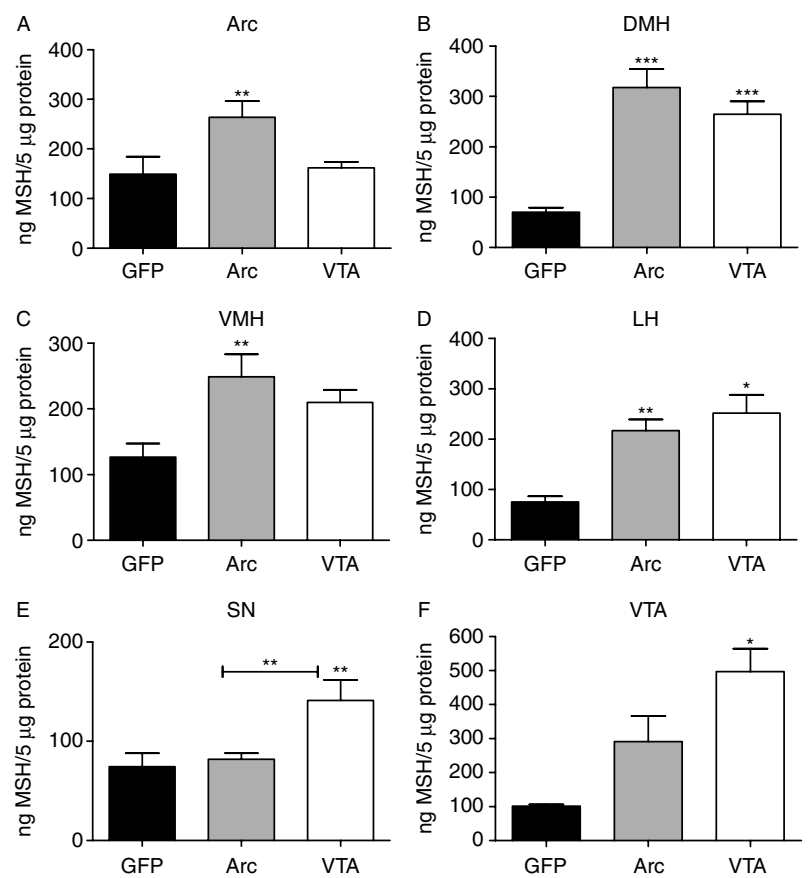

Figure 5 Protein levels of $\alpha-M S H$ in various brain regions. Protein lysates from various brain regions were utilized to assess levels of $\alpha$-MSH using an RIA. As compared with controls, animals injected into the ARC (gray bars) had significant increases in $\alpha$-MSH observed in the (A) arcuate nucleus (ARC),

(B) dorsomedial hypothalamus (DMH), (C) ventromedial hypothalamus $(\mathrm{VMH})$, and the (D) lateral hypothalamus (LH). Animals that were injected into the VTA (white bars) had significant increases in $\alpha-\mathrm{MSH}$ compared with controls in the regions of the $\mathrm{LH}, \mathrm{DMH},(\mathrm{E})$ substantia nigra $(\mathrm{SN})$, and the $(\mathrm{F})$ ventral tegmental area. There was also a significant increase in VTA compared with ARC-injected animals in the regions of the $S N$. Values represent the mean \pm s.E.M. ${ }^{*} P<0 \cdot 01,{ }^{* *} P<0 \cdot 05,{ }^{* * *} P<0 \cdot 001$.

and energy expenditure is unclear, though Lee et al. (2007) attributed it to fatty acid partitioning and energy expenditure. It is difficult to speculate further regarding the mechanism, though we suspect there may be a feedback component supplied by an alternate neurotransmitter pathway. It should also be noted that this uncoupling between energy expenditure and energy intake is in stark contrast to previous experiments in which we have reported decreases in food intake in aged-obese animals on standard chow diets when POMC was overexpressed in either the ARC or the NTS (Li et al. 2003, 2005). This difference in food response could be due to the biological state of the experimental rats (young versus aged and chow versus HF fed). Aged rats are leptin resistant, more susceptible to dietary obesity than young rats and demonstrate a difficulty to normalize caloric consumption when challenged with a HF diet (Judge et al. 2008). Such rats are hyper-responsive to $\alpha-\mathrm{MSH}$ analogs (Scarpace et al. 2003), thus, likely contributing to the heightened anorexic responses to POMC overexpression observed in HF-fed aged rats, but not in the chow-fed young rats in this study.
Despite the lack of decrease in HF food intake, both animals injected into the VTA and those injected in the ARC had significant abatements in body weight gain compared with controls throughout the 100-day duration of the experiment. The diminished body weight gain in the absence of anorexia is suggestive of increased energy expenditure. Accordingly, increased oxygen consumption was observed with POMC overexpression in both the ARC and VTA, with a notable greater increase with treatment in the VTA.

Melanocortins are also known to stimulate non-shivering thermogenesis and previous studies with overexpression in ARC and NTS of aged animals identified increased UCP1 levels in BAT ( $\mathrm{Li}$ et al. 2005, 2007). Indeed, in this study both UCP1 levels in BAT as well as whole-body oxygen consumption were increased in rats with $\mathrm{POMC}$ overexpression in either the ARC or the VTA. Moreover, the significant increases in oxygen consumption were directly correlated with increased UCP1 levels suggesting increase in BAT thermogenesis accounted for the elevated energy expenditure evidenced by heightened whole-body oxygen consumption.

There is no previous evidence that links activation of the VTA with increased BAT UCP1. In this study, injection of the POMC vector into either the ARC or the VTA induced TH protein in both the ARC and VTA. Elevated TH protein indicates increased dopamine biosynthesis (Spector et al. 1965, Fluharty et al. 1985) and is a marker of dopaminergic neurons (Manfredsson et al. 2009). Increased hypothalamic $\mathrm{TH}$ might be one of the mechanisms contributing to the sympathetic nervous system induction of BAT UCP1. Because viral POMC vectors targeted to either the VTA or the ARC elevated TH both in the ARC and VTA, it is possible that VTA-targeted POMC overexpression activates BAT UCP1 secondarily through signals originating from the ARC. However, because UCP1 levels and oxygen consumption were greater with POMC targeted to the VTA, an integrated response involving a contribution from the VTA is also possible.

The POMC overexpression mediated augmentation in energy expenditure and corresponding attenuation in body weight gain were paralleled by decreases in whole-body adiposity as assessed by TD-NMR and fat tissues depot size evaluated at death. In both cases, there were intermediate levels of adipose tissue weights and fat levels in the ARCinjected animals compared with VTA-injected animals. These findings are consistent with the melanocortins' function in lipid catabolism (Seeley et al. 2005). Of note was the gradual but persistent POMC-mediated effect on body weight over the entire course of experimentation. This signifies that mechanisms to promote consistent energy expenditure may potentially contribute to long-lasting effects in weight reduction.

Analysis of the localization of the virus in and around the targeted injection site led to the demonstration that animals with injections into either the ARC or the VTA had the bulk of the viral genomes mostly in the desired areas. The processing of the POMC transcript leads to production of 
$\alpha-\mathrm{MSH}$, the most significant POMC-derived peptide with respect to energy homeostasis among a family of other bioactive peptides. Upon close examination of the resulting $\alpha-\mathrm{MSH}$ levels as a consequence of POMC overexpression targeted into the VTA and ARC, elevated $\alpha-\mathrm{MSH}$ was detected in the ARC as well as in the VMH, DMH, and $\mathrm{LH}$ in the hypothalamus in ARC-injected animals, but not in areas encompassing the VTA or SN. However, the inverse was not true with POMC overexpression in the VTA; elevated $\alpha-\mathrm{MSH}$ was detected in the VTA as well as in the ARC, LH, and $\mathrm{SN}$. This confirms a previous study that gave injections of AAV into the VTA, which resulted in activation of the SN through retrograde transport (Seeley et al. 2005, Cearley \& Wolfe 2007).

The increase in $\boldsymbol{\alpha}-\mathrm{MSH}$ in the ARC as well as the $\mathrm{LH}, \mathrm{VMH}$, and $\mathrm{DMH}$ with POMC overexpression in the VTA suggest that the anorexic effect of $\alpha-\mathrm{MSH}$ in the VTA or ARC may be modified due to activity in any of these other brain regions. For example, $\mathrm{LH}$ and VMH are considered to have opposing effects on hunger and satiety (Mayer \& Thomas 1967, Leibowitz 1970). However, this may not necessarily be the case with respect to POMC action. A study in rats demonstrated that region-specific expression of AgRP in $\mathrm{LH}$ or VMH led to hyperphagia, body weight gain and increased percentage of white adipose tissue (de Backer et al. 2010). This study suggests that the LH and VMH both appear to contain melanocortin receptors and they act in concert, suggesting that the anorexic signals coming from $\alpha-M S H$ in these brain regions may be additive to that in the ARC or VTA.

There is evidence for a direct function of the melanocortin system in the VTA to modulate body weight. For example, a previous report described the introduction of $\alpha-\mathrm{MSH}$ into the VTA and noted an increase in dopamine in the nucleus accumbens (Lindblom et al. 2001). However, it is equally possible that other cleavage products of the POMC peptide, such as ACTH, $\beta$-endorphin or $\gamma$-MSH may mediate the observed physiological effect either directly in the VTA or though projections to other brain regions. Conformation of direct action of $\alpha-\mathrm{MSH}$ in the VTA awaits introduction of $\alpha-\mathrm{MSH}$ or an analog in the VTA, and examination of anorexic and body weight responses. In addition, studies involving the presumed blockade of $\mathrm{MC} 3 / 4 \mathrm{R}$ such as SHU9119 or disruption of the endogenous MC4R activity via site-directed rAAV-mediated shRNA delivery would lead to a better understanding of the mechanism underlying the melanocortin pathway in the VTA.

Collectively, these data demonstrate that overexpression of POMC in the VTA tempers HF-induced weight gain, and the VTA actively participates in that process. However, because modest increases in $\alpha$-MSH in regions other than the specific injection sites were observed, we cannot exclude the possibility that $\boldsymbol{\alpha}$-MSH action in some of these areas account for some or all of the observed weight changes for this group of rats. In addition, other POMC-derived peptides, such as $\beta$-endorphin, $\gamma$-MSH, and ACTH may have participated in the reduction in HF-mediated weight gain.
In summary, we have identified a role for POMC overexpression in the VTA in energy homeostasis, in particular, the abatement of HF-mediated weight and adiposity gain. These attenuated body weights were not accompanied by changes in food consumption, but were associated with increases in TH levels in the ARC and VTA, the thermogenic protein, BAT UCP1, and consequential increases in oxygen consumption. In addition, the VTAinjected animals had significantly less gross amounts of adipose tissue compared with control-treated animals. Virally directed POMC to the VTA activated both the ARC and VTA, which suggests an integrative response that accounts for the observed effects. These new findings warrant further investigation of POMC-derived peptides within the VTA reward center to combat HF-induced obesity.

\section{Declaration of interest}

The authors declare that there is no conflict of interest that could be perceived as prejudicing the impartiality of the research reported.

\section{Funding}

Supported by the National Institute on Aging Grant AG-26159, Neurobiology of Aging Training Grant T32AG00196, Claude D Pepper Older Americans Independence Center NIH P30 AG028740, and the Medical Research Service of the Department of Veterans Affairs.

\section{Author contribution statement}

L M A participated in the design of the experiments, contributed to the major part of experimental work, performed the statistics, and participated in the composition of the manuscript. D J R participated in composition of the manuscript and interpretation of the data. A $S$ provided the scAAV backbone used for cloning the POMC gene and contributed to the experimental work. $\mathrm{M} \mathrm{K} \mathrm{J}$ aided in the killing and tissue harvesting of the animals. M K M contributed to the experimental work. Y Z participated in the composition of the manuscript. K Y C assisted with the oxygen consumption experiments and tissue harvesting. N T contributed to the conception of the study and design of experiments. P J S, the principal investigator, conceived the study, designed the experiments, interpreted the data, and finalized the manuscript.

\section{Acknowledgements}

The authors thank Joel Elmquist and Brad Lowell for providing brain tissue from $M C 4 R$ knockout mice.

\section{References}

Alvaro JD, Tatro JB, Quillan JM, Fogliano M, Eisenhard M, Lerner MR, Nestler EJ \& Duman RS 1996 Morphine down-regulates melanocortin-4 receptor expression in brain regions that mediate opiate addiction. Molecular Pharmacology 50 583-591.

Andino LM, Takeda M, Kasahara H, Jakymiw A, Byrne BJ \& Lewin AS 2008 AAV-mediated knockdown of phospholamban leads to improved contractility and calcium handling in cardiomyocytes. Journal of Gene Medicine 10 132-142. (doi:10.1002/jgm.1131) 
de Backer MW, la Fleur SE, Brans MA, van Rozen AJ, Luijendijk MC, Merkestein M, Garner KM, van der Zwaal EM \& Adan RA 2010 Melanocortin receptor-mediated effects on obesity are distributed over specific hypothalamic regions. International Journal of Obesity 35 629-641. (doi:10.1038/ijo.2010.169)

Balthasar N 2006 Genetic dissection of neuronal pathways controlling energy homeostasis. Obesity 14 (Suppl 5) 222S-227S. (doi:10.1038/oby.2006.313)

Benjannet S, Rondeau N, Day R, Chretien M \& Seidah NG 1991 PC1 and PC2 are proprotein convertases capable of cleaving proopiomelanocortin at distinct pairs of basic residues. PNAS 88 3564-3568. (doi:10.1073/pnas.88. 9.3564)

Berns KI \& Giraud C 1996 Biology of adeno-associated virus. Current Topics in Microbiology and Immunology 218 1-23.

Cannon B \& Nedergaard J 2004 Brown adipose tissue: function and physiological significance. Physiological Reviews 84 277-359. (doi:10.1152/ physrev.00015.2003)

Cearley CN \& Wolfe JH 2007 A single injection of an adeno-associated virus vector into nuclei with divergent connections results in widespread vector distribution in the brain and global correction of a neurogenetic disease. Journal of Neuroscience 27 9928-9940. (doi:10.1523/JNEUROSCI.2185-07. 2007)

Cone RD 2005 Anatomy and regulation of the central melanocortin system. Nature Neuroscience 8 571-578. (doi:10.1038/nn1455)

DeBold CR, Menefee JK, Nicholson WE \& Orth DN 1988 Proopiomelanocortin gene is expressed in many normal human tissues and in tumors not associated with ectopic adrenocorticotropin syndrome. Molecular Endocrinology 2 862-870. (doi:10.1210/mend-2-9-862)

Fluharty SJ, Snyder GL, Zigmond MJ \& Stricker EM 1985 Tyrosine hydroxylase activity and catecholamine biosynthesis in the adrenal medulla of rats during stress. Journal of Pharmacology and Experimental Therapeutics 233 $32-38$.

Garfield AS, Lam DD, Marston OJ, Przydzial MJ \& Heisler LK 2009 Role of central melanocortin pathways in energy homeostasis. Trends in Endocrinology and Metabolism 20 203-215. (doi:10.1016/j.tem.2009.02.002)

Gropp E, Shanabrough M, Borok E, Xu AW, Janoschek R, Buch T, Plum L, Balthasar N, Hampel B, Waisman A et al. 2005 Agouti-related peptideexpressing neurons are mandatory for feeding. Nature Neuroscience $\mathbf{8}$ 1289-1291. (doi:10.1038/nn1548)

Hommel JD, Trinko R, Sears RM, Georgescu D, Liu ZW, Gao XB, Thurmon JJ, Marinelli M \& DiLeone RJ 2006 Leptin receptor signaling in midbrain dopamine neurons regulates feeding. Neuron 51 801-810. (doi:10.1016/j. neuron.2006.08.023)

Judge MK, Zhang J, Tumer N, Carter C, Daniels MJ \& Scarpace PJ 2008 Prolonged hyperphagia with high-fat feeding contributes to exacerbated weight gain in rats with adult-onset obesity. American Journal of Physiology. Regulatory, Integrative and Comparative Physiology 295 R773-R780. (doi:10. 1152/ajpregu.00727.2007)

Kishi T, Aschkenasi CJ, Lee CE, Mountjoy KG, Saper CB \& Elmquist JK 2003 Expression of melanocortin 4 receptor mRNA in the central nervous system of the rat. Journal of Comparative Neurology 457 213-235. (doi:10. 1002/cne.10454)

Lasaga M, Debeljuk L, Durand D, Scimonelli TN \& Caruso C 2008 Role of alpha-melanocyte stimulating hormone and melanocortin 4 receptor in brain inflammation. Peptides 29 1825-1835. (doi:10.1016/j.peptides.2008.06.009)

Lee M, Kim A, Chua SC Jr, Obici S \& Wardlaw SL 2007 Transgenic MSH overexpression attenuates the metabolic effects of a high-fat diet. American Journal of Physiology. Endocrinology and Metabolism 293 E121-E131. (doi:10. 1152/ajpendo.00555.2006)

Leibowitz SF 1970 Reciprocal hunger-regulating circuits involving alpha- and beta-adrenergic receptors located, respectively, in the ventromedial and lateral hypothalamus. PNAS 67 1063-1070. (doi:10.1073/pnas.67.2.1063)

Leriche M, Cote-Velez A \& Mendez M 2007 Presence of proopiomelanocortin mRNA in the rat medial prefrontal cortex, nucleus accumbens and ventral tegmental area: studies by RT-PCR and in situ hybridization techniques. Neuropeptides 41 421-431. (doi:10.1016/j.npep. 2007.08.004)
Li G, Mobbs CV \& Scarpace PJ 2003 Central pro-opiomelanocortin gene delivery results in hypophagia, reduced visceral adiposity, and improved insulin sensitivity in genetically obese Zucker rats. Diabetes 52 1951-1957. (doi:10.2337/diabetes.52.8.1951)

Li G, Zhang Y, Wilsey JT \& Scarpace PJ 2004 Unabated anorexic and enhanced thermogenic responses to melanotan II in diet-induced obese rats despite reduced melanocortin 3 and 4 receptor expression. Journal of Endocrinology 182 123-132. (doi:10.1677/joe.0.1820123)

Li G, Zhang Y, Wilsey JT \& Scarpace PJ 2005 Hypothalamic proopiomelanocortin gene delivery ameliorates obesity and glucose intolerance in aged rats. Diabetologia 48 2376-2385. (doi:10.1007/s00125-005-1943-8)

Li G, Zhang Y, Cheng KY \& Scarpace PJ 2007 Lean rats with hypothalamic pro-opiomelanocortin overexpression exhibit greater diet-induced obesity and impaired central melanocortin responsiveness. Diabetologia $\mathbf{5 0}$ 1490-1499. (doi:10.1007/s00125-007-0685-1)

Lindblom J, Opmane B, Mutulis F, Mutule I, Petrovska R, Klusa V, Bergstrom L \& Wikberg JE 2001 The MC4 receptor mediates alpha-MSH induced release of nucleus accumbens dopamine. Neuroreport 12 2155-2158. (doi:10.1097/00001756-200107200-00022)

Lu L, Wang X, Wu P, Xu C, Zhao M, Morales M, Harvey BK, Hoffer BJ \& Shaham Y 2009 Role of ventral tegmental area glial cell line-derived neurotrophic factor in incubation of cocaine craving. Biological Psychiatry 66 137-145. (doi:10.1016/j.biopsych.2009.02.009)

Luquet S, Phillips CT \& Palmiter RD 2007 NPY/AgRP neurons are not essential for feeding responses to glucoprivation. Peptides 28 214-225. (doi:10.1016/j.peptides.2006.08.036)

Manfredsson FP, Tumer N, Erdos B, Landa T, Broxson CS, Sullivan LF, Rising AC, Foust KD, Zhang Y, Muzyczka N et al. 2009 Nigrostriatal rAAV-mediated GDNF overexpression induces robust weight loss in a rat model of age-related obesity. Molecular Therapy 17 980-991. (doi:10.1038/mt.2009.45)

Mayer J \& Thomas DW 1967 Regulation of food intake and obesity. Science 156 328-337. (doi:10.1126/science.156.3773.328)

McCarty DM, Monahan PE \& Samulski RJ 2001 Self-complementary recombinant adeno-associated virus (scAAV) vectors promote efficient transduction independently of DNA synthesis. Gene Therapy 8 1248-1254. (doi:10.1038/sj.gt.3301514)

Morton GJ, Blevins JE, Kim F, Matsen M \& Figlewicz DP 2009 The action of leptin in the ventral tegmental area to decrease food intake is dependent on Jak-2 signaling. American Journal of Physiology. Endocrinology and Metabolism 297 E202-E210. (doi:10.1152/ajpendo.90865.2008)

Muzyczka N 1992 Use of adeno-associated virus as a general transduction vector for mammalian cells. Current Topics in Microbiology and Immunology 158 97-129.

Savontaus E, Breen TL, Kim A, Yang LM, Chua SC Jr \& Wardlaw SL 2004 Metabolic effects of transgenic melanocyte-stimulating hormone overexpression in lean and obese mice. Endocrinology 145 3881-3891. (doi:10. 1210/en.2004-0263)

Scarpace PJ, Matheny M, Zolotukhin S, Tumer N \& Zhang Y 2003 Leptininduced leptin resistant rats exhibit enhanced responses to the melanocortin agonist MT II. Neuropharmacology 45 211-219. (doi:10.1016/S0028-3908 (03)00158-8)

Seeley RJ, Burklow ML, Wilmer KA, Matthews CC, Reizes O, McOsker CC, Trokhan DP, Gross MC \& Sheldon RJ 2005 The effect of the melanocortin agonist, MT-II, on the defended level of body adiposity. Endocrinology 146 3732-3738. (doi:10.1210/en.2004-1663)

Spector S, Sjoerdsma A \& Udenfriend S 1965 Blockade of endogenous norepinephrine synthesis by alpha-methyl-tyrosine, an inhibitor of tyrosine hydroxylase. Journal of Pharmacology and Experimental Therapeutics 147 86-95.

Tinsley FC, Taicher GZ \& Heiman ML 2004 Evaluation of a quantitative magnetic resonance method for mouse whole body composition analysis. Obesity Research 12 150-160. (doi:10.1038/oby.2004.20)

Received in final form 4 May 2011

Accepted 11 May 2011

Made available online as an Accepted Preprint 12 May 2011 